\title{
The prognostic and diagnostic value of intraleukocytic malaria pigment: an individual patient data pooled meta-analysis of 32,000 patients with severe falciparum malaria in Africa and Asia
}

\author{
Ketsanee Srinamon $^{a, \dagger}$, James A Watson ${ }^{a, b, \dagger *}$, Kamolrat Silamut ${ }^{a, \dagger}$, Benjamas \\ Intharabut $^{a}$, Nguyen Hoan $\mathrm{Phu}^{c}$, Pham Thi Diep ${ }^{c}$, Kirsten E Lyke ${ }^{d}$, Caterina \\ Fanello $^{a, b}$, Lorenz von Seidlein ${ }^{a, b}$, Kesinee Chotivanich ${ }^{a}$, Arjen M Dondorp ${ }^{a, b}$, \\ Nicholas PJ Day ${ }^{a, b}$, Nicholas J White ${ }^{a, b, *}$
}

*For correspondence: jwatowatson@gmail.com; nickw@tropmedres.ac

$\dagger$ Equal contribution

${ }^{a}$ Mahidol Oxford Tropical Medicine Research Unit, Faculty of Tropical Medicine, Mahidol University, Bangkok, 10400, Thailand; ${ }^{b}$ Centre for Tropical Medicine and Global Health, Nuffield Department of Medicine, University of Oxford, New Richards Building, Old Road Campus, Roosevelt Drive, Oxford, OX3 7LG, UK, ${ }^{c}$ Oxford University Clinical Research Unit, Hospital for Tropical Diseases, Ho Chi Minh City, Vietnam, ${ }^{d}$ Center for Vaccine Development and Global Health, University of Maryland School of Medicine, Baltimore, MD, USA.

\begin{abstract}
Background: Severe falciparum malaria is a major cause of death in tropical countries, particularly in African children. Accurate diagnosis and prognostic assessment are critical to clinical management.

Methods: The prognostic value of the malaria parasite count, and the proportions of polymorphonuclear leukocytes (PMNs) and monocytes (PMMs) containing malaria pigment in peripheral blood films were assessed in three randomized controlled trials conducted in severe malaria patients; two in Southeast Asia (AQ Vietnam; $n=483$ and SEAQUAMAT; $n=1,330$ ) and one in Africa (AQUAMAT; $n=4,211$ ). Following a systematic review of the literature, we incorporated these data into an individual patient data meta-analysis including published data from the Severe Malaria in African children (SMAC) network $(n=25,845)$ and a study from Mali $(n=166)$.

Findings: The proportion of pigment containing PMNs on peripheral blood films was strongly positively correlated with prognosis (odds-ratio for in-hospital mortality for a tenfold increase: 2.53 [95\% CI: 2.13-3.00], $p=10^{-26}$ ). The meta-analytic odds-ratio estimate for in-hospital death in patients with $>5 \%$ pigment containing PMNs compared with lower values was 2.67 (95\% CI: 2.08-3.42; $\left.p=10^{-14}\right)$. Particularly in African children, the proportion of pigment containing PMNs added substantially to the prognostic assessment from simple bedside examination, and also to the conventional parasite count. In all analyses, the proportion of pigment containing monocytes had a lower prognostic value.

Interpretation: Microscopy assessment of the proportion of pigment containing PMNs in a blood film is simple and rapid, and should be performed in all patients hospitalised with suspected severe malaria. Patients with $>5 \%$ pigment containing PMNs have more than double the risk of death.

Other: Funded by Wellcome. The systematic review was registered prospectively on PROSPERO, number CRD42021284527
\end{abstract}




\section{Research in context}

Evidence before this study Severe falciparum malaria remains a major cause of preventable childhood mortality in sub-Saharan Africa. In 2019 there were an estimated 274,000 deaths in children under 5 years. Rapidly identifying patients at the greatest risk of death and providing effective treatment is essential to saving lives. Based on data from our prospective studies of strictly defined severe falciparum malaria in Vietnamese adults, the proportions of peripheral blood neutrophils and monocytes containing malaria pigment (haemozoin) was proposed as a prognostic factor for mortality. We carried out a systematic review on PubMed of all articles published between database inception and October 11, 2021, using search terms "intraleukocytic pigment" and "severe malaria". In addition to papers published by our research group, we found two other studies that reported the prognostic value of intraleukocytic pigment counts in severe malaria cohorts of at least 100 patients: the SMAC network study, the largest published cohort study conducted in over 25,000 African children with suspected severe malaria, and a cohort of 172 children from Mali. The SMAC study reported that intraleukocytic malaria pigment counts were not a useful predictor of outcome in African children diagnosed with severe malaria. This differed from the results from the Malian study and our original study in Vietnamese adults.

Added value of this study We provide new data on the prognostic value of intraleukocytic malaria pigment counts in over 6,000 adults and children with a strict diagnosis of severe falciparum malaria studied prospectively in Asia and Africa. These patients were enrolled in three of the largest randomised controlled trials in severe malaria. These randomised trials have provided the main evidence base for current global therapeutic recommendations. Our data show that there is substantial prognostic value in counting intraleukocytic malaria pigment. This was significantly greater for neutrophil rather than monocyte associated pigment. Pooling all the individual patient data showed that the prognostic value was consistent across studies and countries, despite the substantial differences in study populations and study designs. Having more than $5 \%$ pigment containing neutrophils was associated with over double the risk of death from severe falciparum malaria.

Implications of all the available evidence Intraleukocytic malaria pigment counts have substantial prognostic value in severe falciparum malaria. The proportion of neutrophils containing malaria pigment should be counted in thin blood films in all patients with suspected severe malaria. Patients with over $5 \%$ of pigment containing neutrophils have a high risk of death. 


\section{Background}

Severe malaria is a major cause of preventable childhood death in tropical countries, particularly in sub-Saharan Africa. Many factors affecting the prognosis of falciparum malaria have been identified from detailed prospective clinical studies $[1,2,3,4]$. In routine clinical practice in malaria endemic areas the initial assessment of disease severity is made in the clinic or at the bedside from the level of consciousness, vital signs, respiratory pattern and degree of anaemia. If the patient is admitted to hospital then additional valuable laboratory information of prognostic value may become available, notably acid-base status from plasma bicarbonate, lactate or blood gas measurement, plasma creatinine or blood urea, and blood glucose [5]. Rapid tests for blood glucose measurement are widely available and point of care blood lactate measurement is increasingly available in intensive care units.

The diagnosis of malaria is made either from microscopy of stained blood slides or, increasingly, from rapid diagnostic blood tests (RDT). Unfortunately RDTs do not quantify parasitaemia and also do not provide other information of prognostic value. Even small poorly equipped hospitals usually have a microscope. Microscopy malaria parasite counts are still often semi-quantitative in reports (although this is no longer recommended), but additional information of prognostic value may be obtained from counting the malaria parasites, assessing their stage of development [6], and by counting the proportions of leukocytes that have ingested malaria pigment $[7,8,9]$. In many locations only a thick blood film is taken, whereas for counting high density parasitaemias, staging parasite development and assessing intraleukocytic pigment the thin film is easier to read and more accurate. Haemozoin, or malaria pigment, is released at schizont rupture and some of this material is phagocytosed immediately by circulating phagocytic cells. As a result the amount of this particulate material in the circulation reflects the extent of earlier schizogony. Monocytes also ingest malaria pigment but, as they have slower turnover in the circulation than polymorphonuclear leukocytes (PMNs), in blood films (or intradermal smears) malaria pigment in monocytes (PMMs) persists for longer than in PMNs [10]. Although there is general agreement that the proportion of PMNs or PMMs containing intraleukocytic pigment are higher in more severe disease, there is disagreement about its prognostic value [11, 9, 7, 12], notably whether it adds to simple clinical diagnostics. A prospective study in 26,296 patients with a suspected diagnosis of severe falciparum malaria from the SMAC network reported that quantitation of intraleukocytic pigment containing cell counts after adjustment for the main indicators of severity (coma, acidosis, lactate and weight for age z-score) did not provide additional prognostic value [11]. There is therefore uncertainty, and so in routine practice, despite their simplicity, intraleukocytic pigment containing cell counts are generally not reported.

The prognostic value of intraleukocytic pigment was assessed in three of the largest prospective randomised controlled trials of Asian adults and children (AQ Vietnam and SEAQUAMAT) [13, 14] and of African children (AQUAMAT) [15] with severe falciparum malaria. Following a systematic review of the literature, we pooled individual patient data from over 32,000 patients clinically diagnosed with severe malaria and assessed the prognostic value of the proportion of pigment containing PMNs and PMMs.

\section{Methods}

\section{Clinical trials}

These three clinical trials were conducted by associated research teams. The AQ Vietnam trial was a very detailed single centre study in Vietnamese adults with severe falciparum malaria. Intensive clinical and laboratory monitoring was performed by a specialist team in a dedicated ward. This trial provided the basis for the design and conduct of the multi-centre trials conducted in adults and children with severe falciparum malaria in South-East Asia (SEAQUAMAT: mainly adults), and then in Africa (AQUAMAT: mainly children).

\section{AQ Vietnam trial}

The AQ Vietnam trial was a double-blind randomised controlled comparison of intramuscular artemether and intramuscular quinine in 560 Vietnamese adults with strictly defined severe falciparum malaria. It was conducted between May 1991 and January 1996 in a specialist ward of the 
Hospital for Tropical Diseases, Ho Chi Minh City. Malaria blood film microscopy was performed on admission before enrollment. Full details have been published previously [13], and data on the prognostic value of pigment containing PMN and PMM counts were published for the first 300 patients [7].

\section{South East Asian Quinine Artesunate Malaria Trial (SEAQUAMAT)}

The SEAQUAMAT trial was a multicentre open label randomised comparison of parenteral artesunate and parenteral quinine in 1,461 Asian adults and children admitted to hospital with severe falciparum malaria [14]. The participating centres were located in Bangladesh, Myanmar (7 hospitals), India, and Indonesia. Patients over two years of age were included in the study if they had a positive RDT for P. falciparum histidine rich protein 2 (PfHRP2; Paracheck: Orchid Biosystems, Goa, India) and, in the admitting physician's clinical opinion, they had severe malaria, and they or their attendant relative of guardian, gave fully informed written consent. Patients were excluded if there was a convincing history of full treatment with quinine or an artemisinin derivative for more than 24 hours before admission. Full details of the trial have been published previously [14].

\section{The African Quinine Artesunate Malaria Treatment Trial (AQUAMAT)}

The AQUAMAT trial was a multicentre open label randomised comparison of parenteral artesunate and parenteral quinine in 5,425 African children admitted to hospital with severe falciparum malaria [15]. The eleven participating centres in nine countries across Africa were: Hospital Central da Beira, Beira, Mozambique; Royal Victoria Teaching Hospital, Banjul, The Gambia; Komfo Anokye Hospital, Kumasi, Ghana; Kilifi District General Hospital, Kilifi, Kenya; Magunga District Hospital, Korogwe, Tanzania; Teule District Hospital, Muheza, Tanzania; University of Ilorin Teaching Hospital, Ilorin, Nigeria; Mbarara Teaching Hospital, Mbarara, Uganda; Kingasani Health Centre, Kinshasa, DRC; Rwamagana Hospital, Rwamagana, Rwanda and Nyanza Hospital, Nyanza, Rwanda. Children less than 15 years were included in the study if they had a positive RDT for PfLDH (Optimalß) and, in the admitting physician's clinical opinion, they had severe malaria, and they or their attendant relative or guardian gave fully informed written consent. Patients were excluded if there was a convincing history of full treatment with quinine or an artemisinin derivative for more than 24 hours before admission. Overall a third of enrolled patients had cerebral malaria. Full details of the trial have been published previously [15].

\section{Procedures}

In the three trials, an initial clinical assessment was recorded and a peripheral thick and thin blood smear was made for quantitative malaria parasite counting. In the AQ Vietnam study, blood was also taken for immediate haematocrit, blood glucose, plasma lactate and blood gas measurements, blood culture, cross match if necessary, and same day laboratory haematology and biochemistry. Pigment containing leukocytes on the admission blood films were counted later by expert microscopists blinded to the patient outcome. In the SEAQUAMAT and AQUAMAT trials, blood was taken for immediate haematocrit and biochemical analysis using the EC8 + card in a hand held battery operated internally calibrated biochemical analyser (i-STAT, Abbott Laboratories, Il, USA). This provided an immediate hard copy readout with time and date. Parasitised erythrocytes were counted on the Giemsa or reverse Field's stained thin film and reported per 1000 red cells, or if the count was low or the thin film unavailable, was counted in the thick film (and reported as parasites/200WBC). Parasite counts were checked, and parasite staging and leukocyte associated pigment was assessed at the reference laboratory in Bangkok. In each study the numbers of leukocytes containing visible malaria pigment were counted per 100 PMNs and per 30 monocytes under oil immersion microscopy at X1000 magnification on thin blood films (or thick films if the thin film was unavailable).

\section{Ethical review}

The trial protocols were reviewed and approved by each site's appropriate ethical review board (ERBs), and also by the Oxford Tropical Research Ethics committee (OXTREC). 


\section{Systematic review}

We searched PubMed for the terms ('intraleukocytic pigment' OR 'pigment') AND ('severe malaria') to find all studies that measured the proportions of either pigment containing PMNs or pigment containing PMMs in patients diagnosed with severe falciparum malaria. Out of a total of 135 publications, after removing duplicates, reviews, animal studies, studies in non-severe disease and non $P$. falciparum malaria, we identified 12 relevant publications. The median sample size was 46 with a range of 10 to 26,296 . We decided to contact investigators of the three studies which had included 100 or more patients diagnosed with severe malaria $[9,11,16]$. We were unable to obtain the individual patient data from Boeuf et al. [16]. The systematic review was registered prospectively on PROSPERO, number CRD42021284527 (https://www.crd.york.ac.uk/prospero/display_ record. php?RecordID=284527).

\section{Additional Studies}

1. Severe Malaria in African Children (SMAC) SMAC was a multicentre network observational study [17]. The evaluated population comprised all parasitaemic children suspected of having severe malaria who were admitted to each of the participating hospitals of the SMAC network. The SMAC network included sites in 5 countries: Banjul, The Gambia (Medical Research Council Laboratories, Malaria Research Programme, in collaboration with the Royal Victoria Teaching Hospital); Blantyre, Malawi (Blantyre Malaria Project, Queen Elizabeth Central Hospital); Kumasi, Ghana (University of Science and Technology, School of Medical Science); Kilifi, Kenya (Kenya Medical Research Institute for Geographic Medicine); and 2 sites in Gabon, Lambarene and Libreville, both run by the Medical Research Unit of Albert Schweitzer Hospital. All children aged between 1 month and 15 years of age suspected of having malaria and who were sick enough to be hospitalized were screened with a thick blood smear for P. falciparum parasites. Clinical and laboratory measures were documented and children were followed during their hospital admission. Pigment-containing mononuclear leukocytes, and pigmented granulocytes (PMNs) were counted as described by Lell et al. in stained thick blood smears [18]. The numbers of pigment containing monocytes and pigment containing granulocytes were reported per 200 cells. Thus, only a minority of the children in the SMAC study had strictly defined severe malaria. Overall 9.3\% of enrolled patients had coma (BCS $\leq 2)$. Full details have been published previously [11].

2. Mali study: Lyke et al. 172 patients diagnosed with severe malaria were enrolled in Bandiagara, Mali from July 2000 to December 2001 [9]. The proportions of pigment containing PMNs and PMMs were quantitated on thin films by counting $100 \mathrm{PMNs}$ and $30 \mathrm{PMMs}$, respectively. Microscopists were blinded to clinical presentation and outcome. $20 \%$ of patients had coma and 15 patients died $(9 \%)$.

\section{Statistical analysis}

\section{Prognostic value of quantitative microscopy cell counts}

In all analyses we used in-hospital mortality as the primary endpoint (this was the primary endpoint in all three randomised trials). We used the odds-ratio scale to estimate effects. To estimate the relationship between baseline quantitative microscopy cell counts and in-hospital mortality, we fitted univariable generalised additive logistic regression models with mortality as the dependent (outcome) variable, and the baseline counts on the $\log _{10}$ scale as the dependent (predictor) variable. For all the microscopy cell counts, there were a substantial number of zero counts, and the distributions were highly right skewed as a consequence. We used a Box-Cox $\log _{10}(x+\lambda)$ transformation to reduce the right skew whilst accounting for the zero counts where, for the pigment containing PMNS and PMMs, $x$ is expressed as a percentage and $\lambda=0.5$; and for the parasite counts $x$ is the per $\mu \mathrm{L}$ density and $\lambda=50$ (approximately half the lower limit of detection for a thick film). Sensitivity analyses varied these $\lambda$ parameters. For the proportions of pigment containing PMNs and PMMs, estimated odds-ratios for death are sensitive to the choice of the additive parameter in this Box-Cox transformation. The value of $\lambda=0.5$ was chosen as this resulted in approximately the same odds-ratio when analysing all data under the $\log _{10}(x+\lambda)$ transformation, or only the positive count data under a $\log _{10}$ transformation.

The generalised additive logistic regression models were fit using the $\mathrm{R}$ package $m g c v$ which implements penalised regression using smooth splines. We chose a spline based regression approach 
as the association between mortality and baseline quantitative microscopy cell counts could plausibly be non-linear on the logit scale. To avoid over-fitting we set the maximum basis for the smooth spline component to be 4 . Random effect terms were included for country of enrolment and study. Independent models were fitted to the data from Asian adults and children (SEAQUAMAT and AQ Vietnam), and African children (AQUAMAT). In addition we fitted models to all available data from African children (AQUAMAT, SMAC and the Mali study).

\section{Prognostic models adjusted for baseline severity}

To characterise the additional prognostic information of pigmented intraleukocytic count data, we fitted additional prognostic models of death adjusted for known prognostic clinical variables (coma: yes/no; suspected acidosis: yes/no) or known clinical and readily measured laboratory variables (hypoglycaemia: yes/no; blood urea nitrogen; lactate) [4].

Coma was defined in children as a Blantyre coma score (BCS) $\leq 2$ and in adults as a Glasgow coma score $(\mathrm{GCS}) \leq 10$. Suspected acidosis was defined clinically in the SEAQUAMAT and AQUAMAT trials as acidotic breathing; in SMAC as deep breathing (Kussmaul respirations); in the AQ Vietnam study this was not recorded explicitly so we used the proxy variable of respiratory rate. Hypoglycaemia was defined as a blood glucose $\leq 2.2 \mathrm{mmol} / \mathrm{L}$. Lactate was measured in venous plasma for the AQ Vietnam trial and in venous whole blood in the SMAC study. Blood urea nitrogen in SEAQUAMAT and AQUAMAT was measured with the i-stat handheld analyser. The prognostic models were logistic regression models with the binary predictor of $>5 \%$ pigment containing PMNs or PMMs and with nested random intercept terms for hospital, country and study, fitted using the $\mathrm{R}$ package lme4.

\section{Meta-analysis}

To estimate the meta-analytic prognostic value of a pigmented PMN count or a pigmented PMM count $\geq 5 \%$ with respect to in-hospital mortality, we fitted (i) a logistic regression model with nested random effects by hospital, country and study (for SMAC we had data only at the country level except for Gabon); (ii) a logistic regression model assuming random effects across countries and studies. Estimation and visualisation of the meta-analysis was done with the R package meta.

\section{Data availability}

Pigment containing PMN counts and pigmented PMM counts for the AQ Vietnam, SEAQUAMAT and AQUAMAT studies are available along with parasite counts, coma, acidosis and outcome on the github repository (https://doi.org/10.5281/zenodo.5720163). Data from the SMAC network are openly available at: https ://dataverse.harvard. edu/dataset. $x$ html?persistentId=doi : 10.7910/DVN/OCTWUJ

\section{Code availability}

All the code and data are available via a github repository: https://github.com/jwatowatson/ MalariaPigmentPrognosis

\section{Role of the funding source}

The study sponsors had no role in study design; in the collection, analysis, and interpretation of data; in the writing of the report; and in the decision to submit the paper for publication.

\section{Results}

\section{Prognostic value of quantitative microscopy in three randomised trials}

Quantitative pigment containing PMN counts were available for 483 patients from the AQ Vietnam trial; 1,330 patients from the SEAQUAMAT trial; and 4,211 patients from the AQUAMAT trial. For the pigment containing PMMs the corresponding numbers were 301, 1,329, and 4,186, respectively, and for parasite counts were 560,1,457, and 4,786, respectively. Mortality in the patients with available and readable blood slides (where readable means that accurate counting 
Table 1: Pooled individual patient data set. For age we show the median (range). $n$ is the total number of patients enrolled in each study.

\begin{tabular}{|c|c|c|c|c|c|c|c|c|c|}
\hline Study & Countries & Years & $\mathrm{n}$ & Deaths & $\begin{array}{l}\text { Age } \\
\text { (years) }\end{array}$ & Coma & $\begin{array}{l}\text { PMN } \\
\text { counts }\end{array}$ & $\begin{array}{l}\text { PMM } \\
\text { counts }\end{array}$ & $\begin{array}{l}\text { Parasite } \\
\text { counts }\end{array}$ \\
\hline $\begin{array}{ll}\text { AQ } & \text { Vietnam } \\
{[13]} & \end{array}$ & Vietnam & $\begin{array}{l}1991- \\
1996\end{array}$ & 560 & $\begin{array}{l}83 \\
(15 \%)\end{array}$ & $30(15-79)$ & $52 \%$ & 483 & 301 & 560 \\
\hline $\begin{array}{l}\text { SEAQUAMAT } \\
{[14]}\end{array}$ & $\begin{array}{l}\text { Myanmar, } \\
\text { India, } \\
\text { Bangladesh, } \\
\text { Indonesia }\end{array}$ & $\begin{array}{l}2003- \\
2005\end{array}$ & 1461 & $\begin{array}{l}270 \\
(19 \%)\end{array}$ & $25(2-87)$ & $43 \%$ & 1330 & 1329 & 1457 \\
\hline $\begin{array}{l}\text { AQUAMAT } \\
{[15]}\end{array}$ & $\begin{array}{l}\text { Mozambique, } \\
\text { The Gambia, } \\
\text { DRC, Tanzania, } \\
\text { Kenya, Rwanda, } \\
\text { Nigeria, Ghana, } \\
\text { Uganda }\end{array}$ & $\begin{array}{l}2005- \\
2010\end{array}$ & 5425 & $\begin{array}{l}527 \\
(10 \%)\end{array}$ & $2(0-14)$ & $36 \%$ & 4211 & 4186 & 4786 \\
\hline SMAC [11] & $\begin{array}{l}\text { The Gambia, } \\
\text { Kenya, Malawi, } \\
\text { Ghana, Gabon }\end{array}$ & $\begin{array}{l}2000- \\
2005\end{array}$ & 26389 & $\begin{array}{l}1136 \\
(4 \%)\end{array}$ & $2.2(0-15)$ & $9 \%$ & 25845 & 25025 & 26199 \\
\hline Lyke et al. [9] & Mali & $\begin{array}{l}2000- \\
2001\end{array}$ & 172 & $15(9 \%)$ & $\begin{array}{l}2.5 \\
10.4)\end{array}$ & $21 \%$ & 166 & 166 & 172 \\
\hline
\end{tabular}

was possible) and those without slides were comparable in the SEAQUAMAT and AQUAMAT trials. In both trials, higher parasitaemia correlated with improved slide readability, with $70 \%$ of readable slides $(1,010$ out of 1,420$)$ in patients with parasite densities less than 10,000 per $\mu \mathrm{L}$ versus $89 \%$ of readable slides $(4,283$ out of 4,823$)$ in patients with parasite densities above 10,000 per $\mu \mathrm{L}$.

We compared the prognostic value of pigment containing PMNs, pigment containing PMMs, and standard malaria parasite counts in Asian adults and children and African children by fitting flexible generalised additive logistic models to in-hospital mortality (Figure 1). The prognostic value of peripheral blood malaria parasite counts differed substantially for Asian adults and children versus African children. Low parasite counts $(<1,000$ per $\mu \mathrm{L})$ were associated with slightly higher than average mortality in African children (AQUAMAT, $p=0.005$ for the spline fit). This is most likely explained by mis-classification of severe disease, i.e. misdiagnosing severe (usually bacterial) illness and incidental parasitaemia as severe falciparum malaria [19]. It has been estimated that approximately one third of children in sub-Saharan Africa with an initial diagnosis of severe malaria are misclassified [20,21]. In Asian adults and children, in whom the diagnosis of severe malaria is more specific, mortality rose steeply for parasite counts $>10,000$ per $\mu \mathrm{L}\left(p=10^{-11}\right.$ for the spline fit) and there was no significant increase in mortality at low parasite densities. The prognostic value of pigment containing PMNs was consistent across Asian adults and children, and African children, with higher mortality for higher counts $\left(p=10^{-8}\right.$ and $p=10^{-16}$ for the spline fits, respectively). The effect was strongest in the Asian adults and children, where the mortality in patients with $20 \%$ or more of pigment containing PMNs was at least three times greater than in those with no pigment containing PMNs ( $>30 \%$ vs $<10 \%$, respectively). By contrast pigment containing PMMs had a lower prognostic value although the quantitative counts were correlated with in-hospital mortality $(p=0.02$ and $p=0.005$ for Asian adults and chidren, and African children, respectively).

We fitted a mixed effects logistic regression model to in-hospital mortality, combining individual patient data from the three randomised trials (nested random effects per site, country and study). A ten-fold increase in the pigment containing PMN count was associated with an odds-ratio for death of 2.53 (95\% CI 2.13-3.00, $\left.p=10^{-26}\right)$. A ten-fold increase in the pigment containing PMM count was associated with an odds-ratio for death of $1.39\left(95 \%\right.$ CI: $\left.1.21-1.59, p=10^{-6}\right)$.

\section{Individual patient meta-analysis of intraleukocytic malaria pigment counts}

A systematic review of the literature identified three previously published studies which recorded intraleukocytic pigment in over 100 patients with severe malaria $[9,11,16]$. We obtained individual patient data from two of these studies [9, 11]. We conducted an individual patient data metaanalysis using the pooled data set (overview given in Table $1, n=32,035$ patients with data on the proportion of pigment containing PMNs, $n=31,007$ patients with data on the proportion of pigment containing PMMs, and $n=33,174$ patients with malaria parasite densities). There were no identified issues with data integrity in the pooled studies. 
medRxiv preprint doi: https://doi.org/10.1101/2021.11.30.21267052; this version posted December 7, 2021. The copyright holder for this preprint (which was not certified by peer review) is the author/funder, who has granted medRxiv a license to display the preprint in perpetuity.
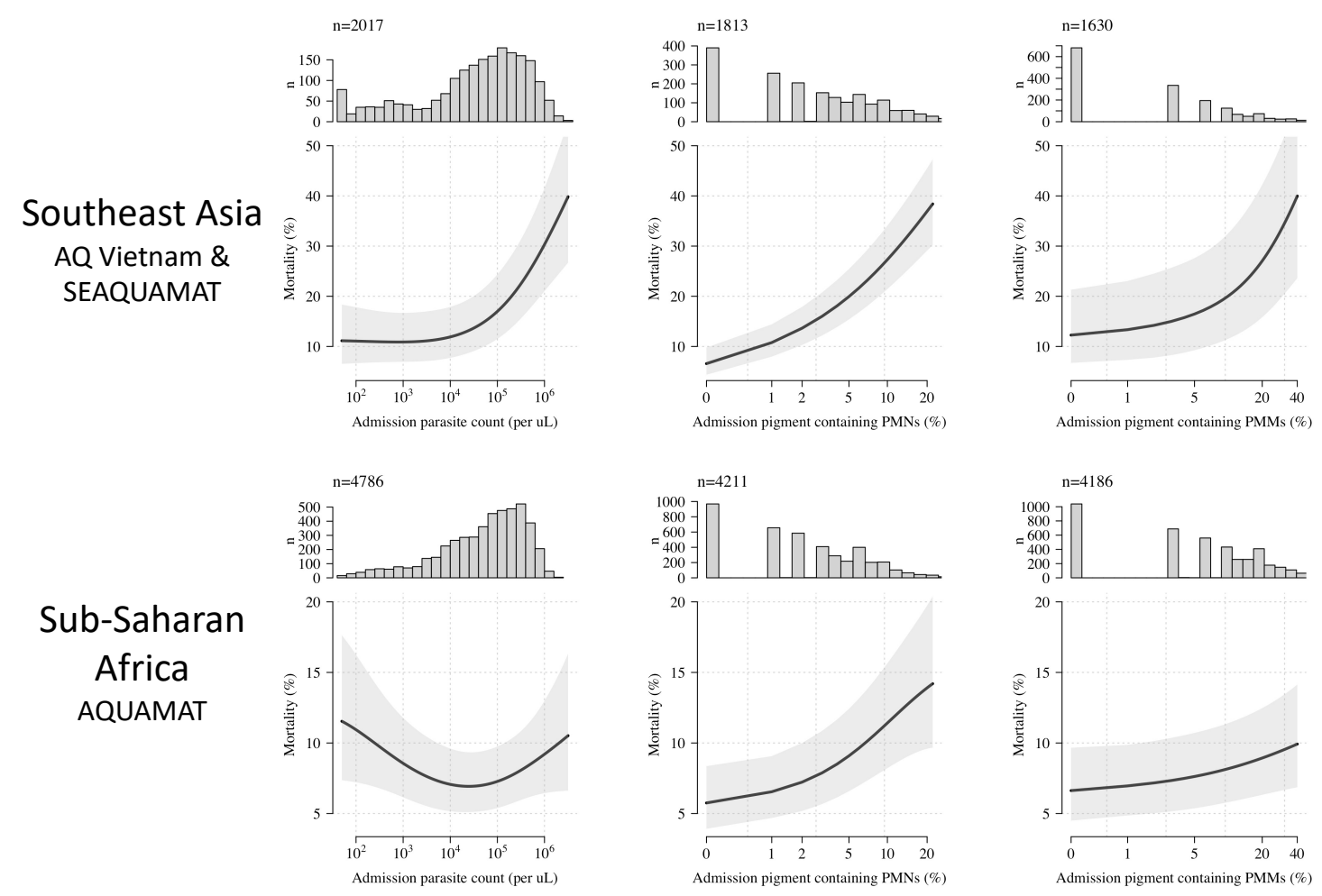

Figure 1: Prognostic value of quantitative microscopy cell counts in Asian adults and children (top panels: AQ Vietnam and SEAQUAMAT trials) and African children (bottom panels: AQUAMAT trial) with severe falciparum malaria. Each histogram shows the number of patients with available data. The black lines (grey shaded areas) show the mean (95\% confidence interval) predicted mortality as a function of each quantitative count, estimated using a generalised additive logistic regression model (fitted using $m g c v$ in $R$, with random effects per study site and 4 degrees of freedom). Note the y-axis scales are different for the Asian adults and African children. The $\mathrm{x}$-axes are on a $\log _{10}$ scale, showing $99 \%$ of the range of observed values. For the PMN and PMM, the $\mathrm{x}$-axes shows a $\log _{10} x+0.5$ transformation (where $x$ is expressed a percentage) 

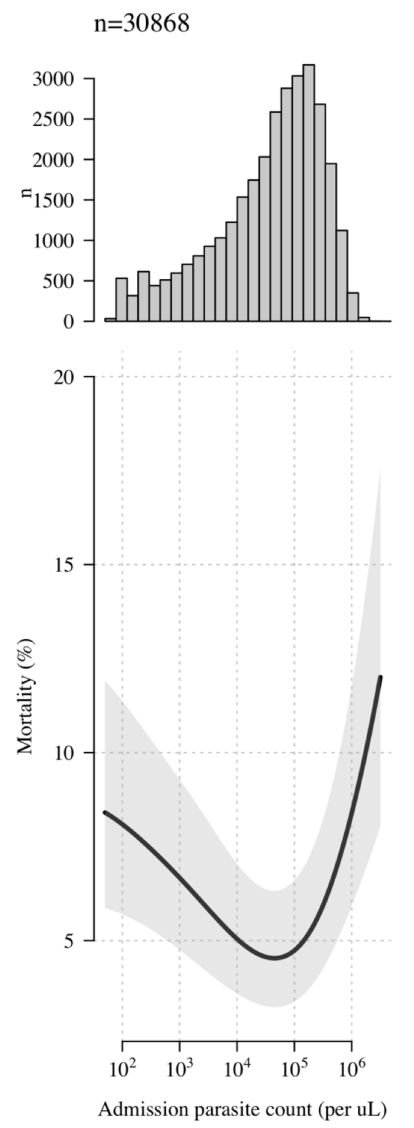

$\mathrm{n}=30222$
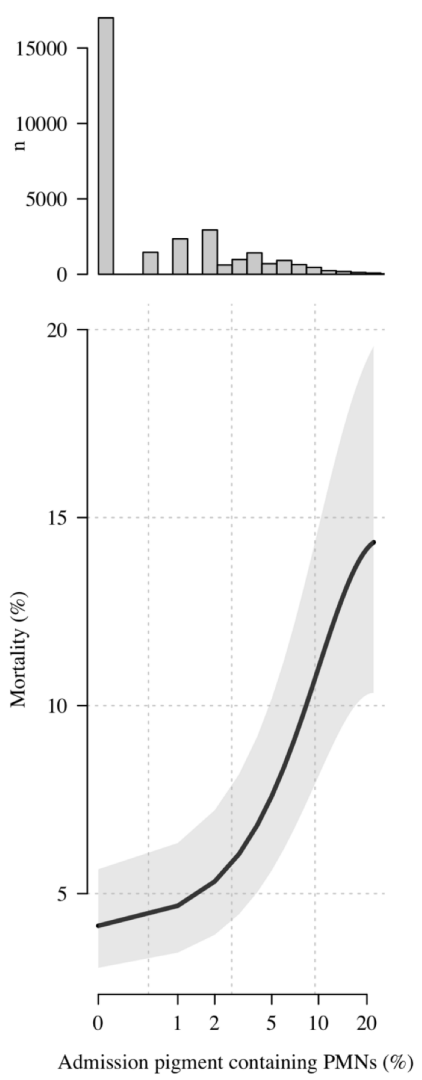

$\mathrm{n}=29377$
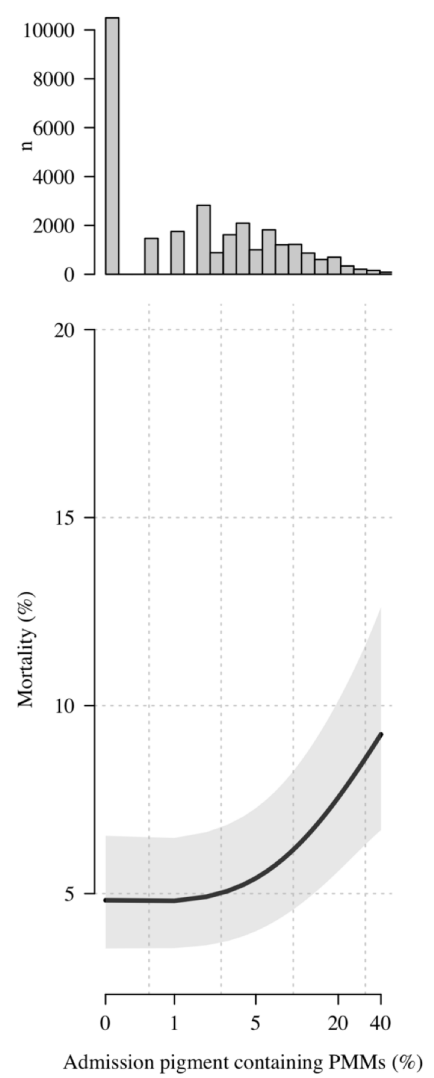

Figure 2: The prognostic value of quantitative microscopy cell counts in over 30,000 children from 12 countries across sub-Saharan Africa in three studies (AQUAMAT [15], SMAC [11], and Lyke et al. [9]). The histograms in the top panels show the count distribution for each variable (from left to right: parasite density, pigment containing PMNs, and pigment containing PMMs). The bottom panels show the estimated relationships between the counts and in-hospital mortality. The black lines (grey shaded areas) show the mean (95\% confidence interval) predicted mortality as a function of each quantitative count, estimated using a generalised additive logistic regression model (fitted using $m g c v$ in $R$, with random intercept terms per study site and 4 degrees of freedom).

\section{Prognostic value of quantitative microscopy counts in African children}

In our pooled dataset, 30,868 African children had recorded parasite densities; 30,222 had recorded proportions of pigment containing PMNs, and 29,377 had recorded proportions of pigment containing PMMs. Figure 2 shows the estimated relationships between the quantitative microscopy counts and in-hospital mortality, using generalised additive regressions models with random effect terms for each study and each study site. As observed in the AQUAMAT trial, there was a 'U-shaped' relationship between the parasite count and a fatal outcome, with both low parasitaemia $(<10,000$ per $\mu \mathrm{L})$ and hyperparasitaemia $(>100,000 \mu \mathrm{L})$ associated with an increased risk of death ( $p=10^{-16}$ for the spline fit). The proportions of pigment containing PMNs and pigment containing PMMs were both strongly positively correlated with in-hospital mortality, with the strongest mortality increase observed for proportions of pigment containing PMNs greater than $5 \%\left(p=10^{-40}\right.$ and $p=10^{-10}$ for the spline fits for the pigment containing PMNs and PMMs, respectively).

\section{Prognostic value of $>5 \%$ pigment containing PMNs}

In the pooled data set, the greatest increase in mortality was seen in patients with $>5 \%$ pigment containing PMNs (Figure S2). When comparing mortality outcomes in patients with $>5 \%$ pigment containing PMNs versus $\leq 5 \%$ pigment containing PMNs, pooling all available data we obtained a 


\begin{tabular}{|c|c|c|c|c|}
\hline \multirow{3}{*}{$\begin{array}{l}\text { Study } \\
\text { AQ: Vietnam }\end{array}$} & \multirow{2}{*}{\multicolumn{2}{|c|}{$\begin{array}{r}>5 \% \mathrm{pPMN} \\
\text { Events Total }\end{array}$}} & \multicolumn{2}{|c|}{$<5 \%$ pPMN } \\
\hline & & & Events & Total \\
\hline & 33 & 93 & 33 & 390 \\
\hline SEAQUAMAT: Bangladesh & 60 & 171 & 54 & 239 \\
\hline SEAQUAMAT: Myanmar & 56 & 226 & 26 & 327 \\
\hline SEAQUAMAT: Indonesia & 11 & 32 & 12 & 201 \\
\hline SEAQUAMAT: India & 17 & 54 & 15 & 80 \\
\hline AQUAMAT: Mozambique & 11 & 89 & 27 & 310 \\
\hline AQUAMAT: DRC & 8 & 66 & 7 & 313 \\
\hline AQUAMAT: Ghana & 4 & 101 & 8 & 194 \\
\hline AQUAMAT: Nigeria & 13 & 66 & 18 & 218 \\
\hline AQUAMAT: Kenya & 26 & 143 & 10 & 160 \\
\hline AQUAMAT: Tanzania & 72 & 394 & 99 & 828 \\
\hline AQUAMAT: Rwanda & 5 & 35 & 7 & 170 \\
\hline AQUAMAT: The Gambia & 15 & 101 & 36 & 385 \\
\hline AQUAMAT: Uganda & 6 & 90 & 30 & 548 \\
\hline SMAC: The Gambia & 21 & 97 & 305 & 3346 \\
\hline SMAC: Ghana & 73 & 688 & 238 & 6108 \\
\hline SMAC: Kenya & 31 & 598 & 214 & 6197 \\
\hline SMAC: Gabon (Lambarene) & 7 & 294 & 19 & 1518 \\
\hline SMAC: Gabon (Libreville) & 13 & 109 & 75 & 1616 \\
\hline SMAC: Malawi & 11 & 57 & 124 & 5217 \\
\hline Lyke et al: Mali & 6 & 41 & 9 & 125 \\
\hline $\begin{array}{l}\text { Common effect model } \\
\text { Random effects model } \\
\text { Heterogeneity: } I^{2}=68 \%, \tau^{2}= \\
\text { Test for overall effect (randon }\end{array}$ & , & 3545 & 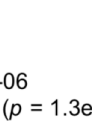 & 28490 \\
\hline
\end{tabular}

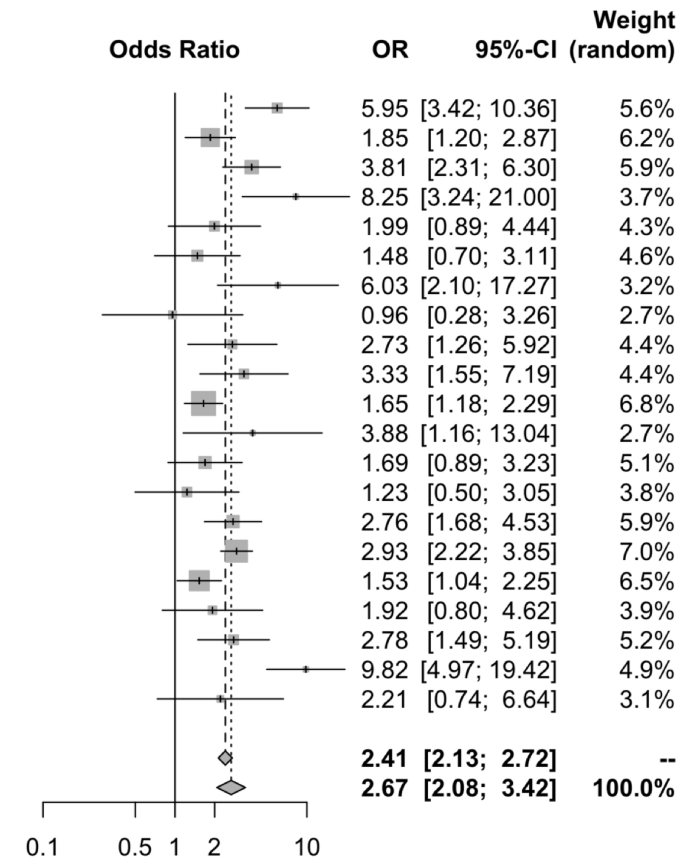

Figure 3: Meta-analysis of the prognostic value for mortality of $>5 \%$ versus $\leq 5 \%$ pigment containing PMNs (pPMN) in 32,035 patients clinically diagnosed with severe falciparum malaria. We show the individual estimates broken down by country of enrolment for each study except for SMAC, Gabon where the distribution of pigment containing PMNs was substantially different between the two sites (Lambaréné and Libreville).

meta-analytic estimate of the odds-ratio for in-hospital death of 2.67 (95\% CI: 2.08-3.42, $p=10^{-14}$, Figure 3). In comparison, comparing mortality outcomes in patients with $>5 \%$ pigment containing monocytes versus $\leq 5 \%$ pigment containing monocytes, the meta-analytic estimate of the odds-ratio for in-hospital death was 1.37 (95\% CI: 1.11-1.67, $p=10^{-3}$, Figure S3). If we assume a baseline risk of death of $5 \%$, then an odds-ratio for death of 2.67 translates to a risk ratio of approximately 2.5 , i.e. a mortality of $12.5 \%$ in patients with $>5 \%$ pigment containing PMNs compared to a mortality of $5 \%$ in patients with $\leq 5 \%$ pigment containing PMNs.

\section{Prognostic value of intraleukocytic malaria pigment in addition to clinical and laboratory signs of severity}

The utility of a prognostic test in severe malaria depends on whether it adds information to simple bedside assessment. With the exception of blood glucose, laboratory tests are not usually available immediately at point of care in the rural tropics -whereas most facilities do have a microscope (although unfortunately clean slides, good quality stains and anhydrous methanol are often not available). We assessed the prognostic value of $>5 \%$ pigment containing PMNs and $>5 \%$ pigmented PMMs before and after adjustment for known highly prognostic clinical and laboratory variables (Figure 4). The clinical variables were coma (yes/no) and Kussmaul's breathing (for AQ Vietnam this was not recorded specifically so we used the respiratory rate as a proxy); the laboratory variables were hypoglycaemia and either lactate (for AQ Vietnam and SMAC) or blood urea nitrogen (for SEAQUAMAT and AQUAMAT). The study by Lyke et al. did not have any data on admission severity apart from coma so we omitted it from this analysis. The results show clearly 

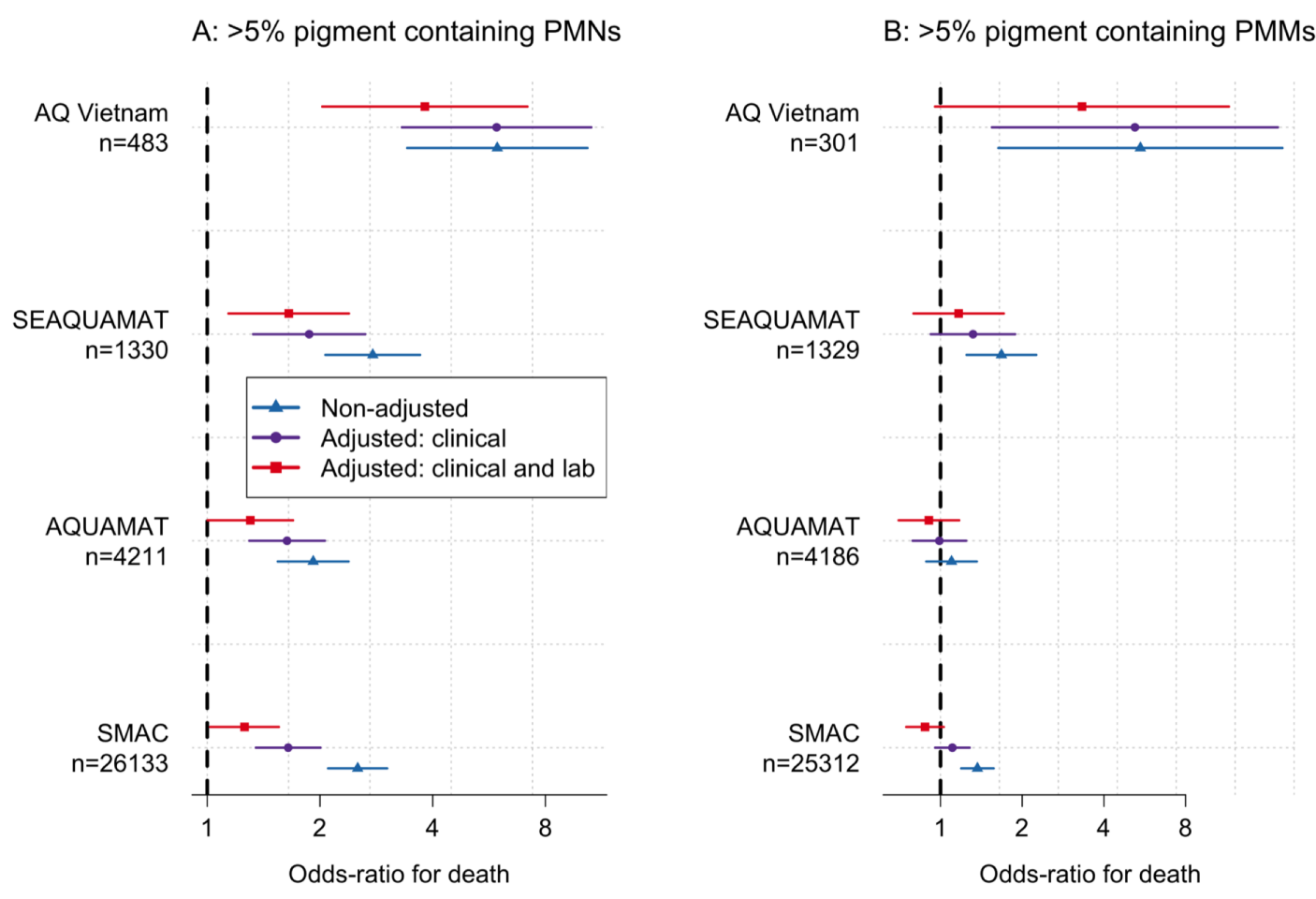

Figure 4: The prognostic value of intraleukocytic pigment counts in severe falciparum malaria with and without adjustment for known prognostic clinical and laboratory variables (clinical: coma and acidosis; laboratory hypoglycaemia and either lactate for AQ Vietnam and SMAC or blood urea nitrogen for SEAQUAMAT and AQUAMAT).

that pigment containing PMN counts provided additional prognostic information over that of the bedside clinical assessment and even laboratory biomarkers. In African children the additional prognostic value was substantial.

\section{Relationship between malaria parasite density and intraleukocytic pig- ment}

We compared peripheral parasite densities to the intraleukocytic pigment counts in the pooled data set (Figure S4). The peripheral parasite density was highly predictive of having $>5 \%$ pigment containing PMNs or PMMs (for a ten-fold increase in parasitaemia, the odds-ratio for having $>5 \%$ pigmented PMNs was 2.4 [95\% CI: 2.3-2.6], and the odds-ratio for having $>5 \%$ pigment containing PMMs was 1.7 [95\% CI: 1.6-1.7]). This translated roughly to less than 1 in 20 patients with parasite densities under 1,000 per $\mu \mathrm{L}$ having pigment containing PMNs $>5 \%$, compared to 1 in 5 patients with hyperparasitaemia $(>100,000$ per $\mu \mathrm{L})$.

\section{Diagnostic value of intraleukocytic malaria pigment in severe illness}

Plasma PfHRP2 is the best available biomarker for the assessment of the sequestered parasite biomass in severe malaria [19]. The diagnosis of severe malaria is highly specific for patients with a plasma PfHRP2 concentration $\geq 1,000 \mathrm{ng} / \mathrm{ml}[21]$. We assessed the diagnostic value of the proportion of pigment containing PMNs and PMMs by comparing their values with the plasma PfHRP2 concentrations in patients from the AQUAMAT trial in which both were measured. Plasma PfHRP2 concentrations and proportions of pigment containing PMNs and PMMs were jointly available for a total of 2,933 and 2,913 patients from the AQUAMAT trial, respectively. In total 1,890 of these patients (64\%) had a plasma PfHRP2 concentration above 1,000 ng/ml. The proportions of pigment containing PMNs and pigment containing PMMs were both highly correlated with plasma PfHRP2 concentrations $\geq 1,000 \mathrm{ng} / \mathrm{mL}$ (Figure $5, p=10^{-26}$ and $p=10^{-15}$ for a mixed effects logistic regression model fits, respectively). In patients with $\leq 5 \%$ pigment 
containing PMNs, 1,306 out of 2,178 (60\%) had a plasma PfHRP2 $\geq 1,000 \mathrm{ng} / \mathrm{mL}$. In comparison, in patients with $>5 \%$ pigment containing PMNs, 583 out of 755 (77\%) had a plasma Pf HRP2 $\geq 1,000 \mathrm{ng} / \mathrm{mL}$. The corresponding proportions with less than and greater than $5 \%$ pigment containing PMMs were 672 out of 1208 (56\%) and 1204 out of 1705 (71\%), respectively.

\section{Discussion}

Severe falciparum malaria is estimated to kill over 1000 people each day. Most of these deaths are in young children in Africa. Rapid recognition of the disease and administration of artesunate are important determinants of outcome. In hospitals and health centres confirmation of the diagnosis of malaria and recognition of the three major clinical components of severe malaria (coma, acidotic breathing, severe anaemia) can be done immediately. Rapid diagnostic tests are increasingly used to diagnose malaria even in hospitals, with less use of microscopy than in previous years. Indeed there are concerns that microscopy proficiency and support are declining in malaria endemic areas. But microscopy of thin and thick blood films provides important prognostic information which the current rapid tests do not. Thick blood films must be dried thoroughly but thin blood films can be fixed and then read immediately. In addition to the malaria parasite count (the proportion of red cells containing one or more parasites), their stage of development can be assessed, and the proportion of leukocytes containing ingested malaria pigment can be counted. Polymorphonuclear leukocytes (PMNs: granulocytes; nearly all neutrophils) are more abundant than monocytes, are readily identified, and an assessment of 100 cells in the tail of the thin blood film usually usually takes only a few minutes. This study, which used prospective assessments from three of the largest randomized controlled trials in severe falciparum malaria, and then combined these within an individual patient data meta-analysis of all the large studies which recorded interleukocytic pigment data, shows clearly the prognostic value of counting the proportion of PMNs with intraleukocytic malaria pigment. This count provides substantial additional prognostic information above that provided by a simple rapid bedside assessment.

As previously reported, the peripheral blood parasite density is a poor prognosticator in severe malaria in African children [4], with a non-linear 'U-shaped' relationship to in-hospital mortality. This is because the peripheral parasite density reflects poorly the sequestered parasite burden [19] and because severe malaria is frequently misdiagnosed. In much of Africa, where malaria transmission is high, differentiating severe malaria from other causes of severe childhood illness is difficult [20, 21, 22]. Asymptomatic parasitaemia is common and so many children are diagnosed as having severe malaria, whereas in fact they have another severe illness (usually bacterial sepsis) and incidental parasitaemia [23]. Thus, our assessment of the prognostic value of the intraleukocytic malaria pigment counts in true severe malaria may be an underestimate in studies of African children as mortality was higher than average in the children who probably did not have malaria (Figure 2).

Sequestration of parasitised erythrocytes in the venules and capillaries of vital organs is the fundamental pathophysiological process in severe malaria [24, 22]. The concentrations of Pf HRP2 and parasite DNA in plasma are quantitative measures of the preceding hidden sequestered parasite burden as both are liberated into the circulating plasma at schizont rupture. Both measurements correlate strongly with disease severity [19, 25]. Clinically the obstructed microcirculation in the retinal, buccal or rectal circulations can be visualized [26]. Indirect ophthalmoscopy by an experienced clinician can identify characteristic retinal and vascular changes which are highly specific for falciparum malaria as the cause of coma. However these approaches require special training and relevant equipment at the bedside, and they are generally not performed. Quantifying the proportion of pigment containing neutrophils on a thin blood film is a simple, inexpensive and more rapid alternative way to assess the sequestered biomass. PfHRP2 remains in the circulation for days, and so accumulates with successive schizogony whereas $P$. falciparum DNA and haemozoin are removed more rapidly from the circulation. The rate of removal of haemozoin depends on the turnover and clearance of the cells which have phagocytosed it. PMN counts in severe malaria are usually normal or slightly raised. PMNs have substantially more rapid turnover than PMMs, with a half-life in the circulation of about 19 hours compared to 45 hours [10]. Thus, the proportion of PMNs containing intraleukocytic pigment is a function of the amount of recent schizogony. This explains its prognostic value. By contrast monocytes which have ingested pigment reflect a longer time course and are associated with anaemia [27]. The number of monocytes with intraleukocytic malaria pigment still has prognostic value, but much less so than for PMNs. The blood cell counts 


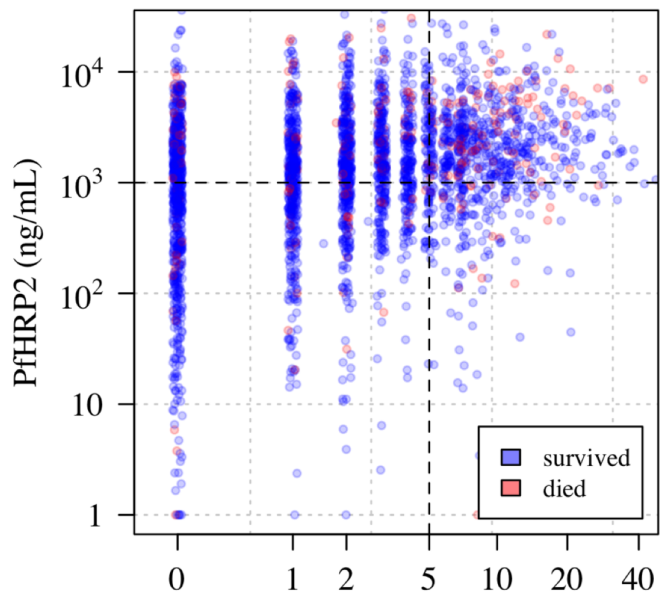

Pigment containing PMNs (\%)

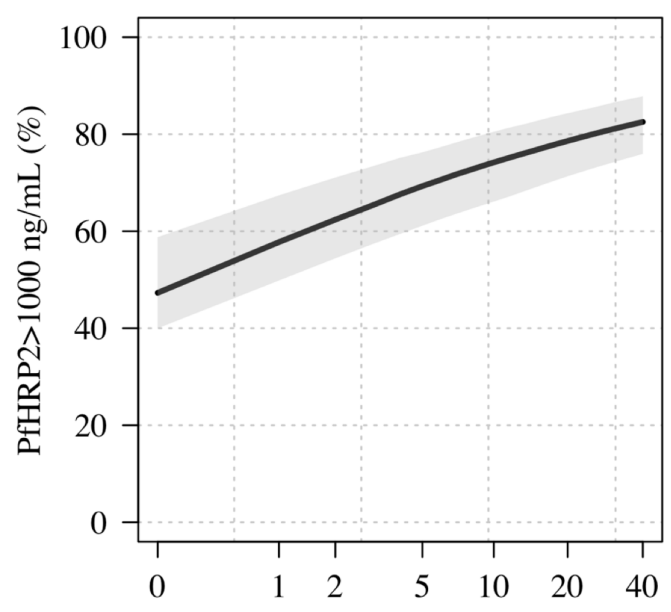

Pigment containing PMNs $(\%)$

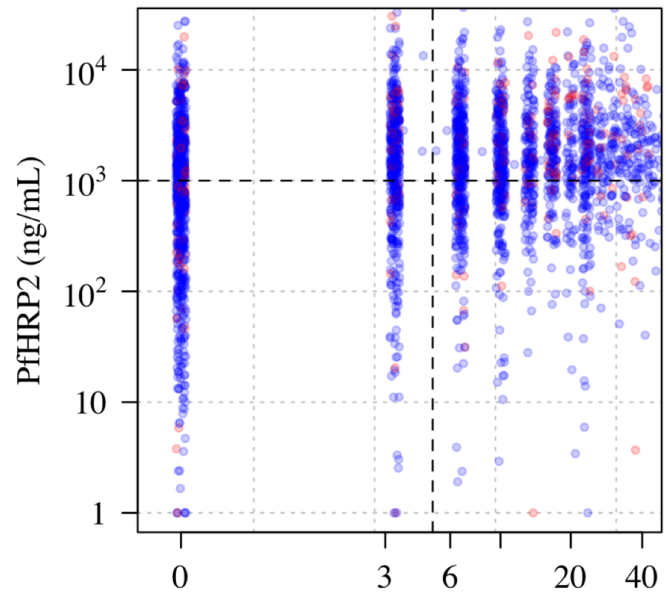

Pigment containing PMMs (\%)

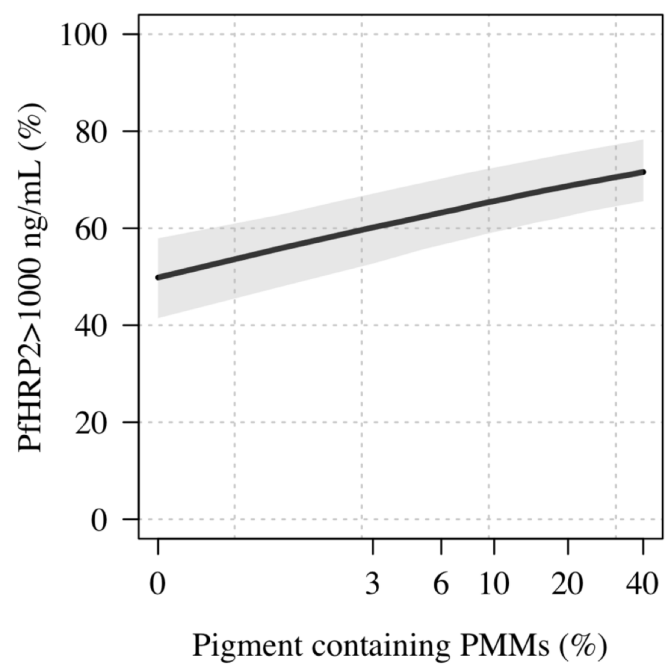

Figure 5: The diagnostic value of pigment containing PMNs and PMMs in severe falciparum malaria. The top panels show scatterplots of the proportion of pigment containing PMNs and PMMs against the plasma PfHRP2 concentration, in 2,933 patients from the AQUAMAT trial who had both measurements recorded. The bottom panels show the estimated probability of having a plasma PfHRP2 concentration $>1000 \mathrm{ng} / \mathrm{ml}$ as a function of the pigment containing intraleukocytic count (using a mixed effects logistic regression model). 
also inform the diagnosis. Finding PMNs with intraleukocytic malaria pigment points strongly to malaria as the cause of severe illness. Higher platelet counts, higher white blood cell counts, absence of PMNs containing pigment and low parasite counts all point towards an alternative diagnosis to malaria as the cause of severe illness [20,21].

Although it is recommended that both thin and thick blood films are taken from patients suspected of having severe malaria, in many centres only the thick film is performed [17]. Quality thin films require clean glass slides, filtered stains, anhydrous methanol, and good technique. But they are much easier to read, they provide more accurate counts in high density infections, and they also allow more accurate staging of parasite development. Thick films take time to dry, and are more difficult to evaluate accurately because cellular morphology is contracted, and artefacts and stain precipitates may be mistaken for pigment. The speed and simplicity of this rapid test is particularly important in rural settings with limited access to laboratory support. Where there is a microscope thin film assessment should be a routine part of the assessment of any patient suspected of having severe falciparum malaria. Microscopy cell counts are also necessary for cerebrospinal fluid assessment, amongst many other dignostic benefits. Health systems should support maintenance of quality microscopy. New inexpensive cell phone adapted automated methods of microscopy cell counting are now being developed and evaluated which may be adaptable to parasite counting, staging and neutrophil pigment assessment [28].

Our conclusions differ from those of the SMAC network analysis [11]. Their retrospective data analysis concluded that "although high levels of pigmented cells were associated with a fatal outcome in some study sites, they were not useful predictors of outcome across Africa" and that "they were not useful markers of fatal outcome for individual patients". Reanalysis of the SMAC data shows that although the studied children had a much broader range of disease severities (i.e. in contrast to the randomised controlled trials evaluated here, a substantial proportion of children in the SMAC database did not have severe malaria and the overall mortality was low), and thick blood films rather than thin films were evaluated, the results of the five malaria studies are highly consistent. The proportion of PMNs containing malaria pigment has strong diagnostic and prognostic value, and importantly it adds significantly to the bedside assessment of coma and acidotic breathing.

\section{References}

[1] WHO. Severe Malaria. Tropical Medicine \& International Health. 2014;19(Supplement 1):7131. doi:10.1111/tmi.12313_2.

[2] English M, Waruiru C, Amukoye E, Murphy S, Crawley J, Mwangi I, et al. Deep breathing in children with severe malaria: indicator of metabolic acidosis and poor outcome. The American Journal of Tropical Medicine and Hygiene. 1996;55(5):521-524.

[3] Molyneux M, Taylor T, Wirima J, Borgsteinj A. Clinical features and prognostic indicators in paediatric cerebral malaria: a study of 131 comatose Malawian children. QJM: An International Journal of Medicine. 1989;71(2):441-459.

[4] Von Seidlein L, Olaosebikan R, Hendriksen IC, Lee SJ, Adedoyin OT, Agbenyega T, et al. Predicting the clinical outcome of severe falciparum malaria in African children: findings from a large randomized trial. Clinical Infectious Diseases. 2012;54(8):1080-1090.

[5] Newton CRJC, Valim C, Krishna S, Wypij D, Olola C, Agbenyega T, et al. The Prognostic Value of Measures of Acid/Base Balance in Pediatric Falciparum Malaria, Compared with Other Clinical and Laboratory Parameters. Clinical Infectious Diseases. 2005;41(7):948-957.

[6] Silamut K, White NJ. Relation of the stage of parasite development in the peripheral blood to prognosis in severe falciparum malaria. Transactions of The Royal Society of Tropical Medicine and Hygiene. 1993;87(4):436-443. doi:10.1016/0035-9203(93)90028-O.

[7] Phu NH, Day N, Diep PT, Ferguson DJP, White NJ. Intraleucocytic malaria pigment and prognosis in severe malaria. Transactions of The Royal Society of Tropical Medicine and Hygiene. 1995;89(2):200-204. doi:10.1016/0035-9203(95)90496-4.

[8] Metzger WG, Mordmüller BG, Kremsner PG. Malaria pigment in leucocytes. Transactions of the Royal Society of Tropical Medicine and Hygiene. 1995;89(6):637-638. 
[9] Lyke KE, Diallo DA, Dicko A, Kone A, Coulibaly D, Guindo A, et al. Association of intraleukocytic Plasmodium falciparum malaria pigment with disease severity, clinical manifestations, and prognosis in severe malaria. The American journal of tropical medicine and hygiene. $2003 ; 69(3): 253-259$.

[10] Day NPJ, Diep PT, Ly PT, Sinh DX, Loc PP, Chuong LV, et al. Clearance Kinetics of Parasites and Pigment-Containing Leukocytes in Severe Malaria. Blood. 1996;88(12):46944700. doi:https://doi.org/10.1182/blood.V88.12.4694.bloodjournal88124694.

[11] Kremsner PG, Valim C, Missinou MA, Olola C, Krishna S, Issifou S, et al. Prognostic value of circulating pigmented cells in African children with malaria. The Journal of infectious diseases. 2009;199(1):142-150.

[12] Willmann M, Ahmed A, Siner A, Wong T, Woon LC, Singh B, et al. Laboratory markers of disease severity in Plasmodium knowlesi infection: a case control study. Malaria journal. $2012 ; 11(1): 1-9$.

[13] Hien TT, Day NP, Phu NH, Mai NTH, Chau TTH, Loc PP, et al. A controlled trial of artemether or quinine in Vietnamese adults with severe falciparum malaria. New England Journal of Medicine. 1996;335(2):76-83.

[14] Dondorp AM, Nosten F, Stepniewska K, Day NP, White NJ. Artesunate versus quinine for treatment of severe falciparum malaria: a randomised trial. The Lancet. 2005;366(9487):717725 .

[15] Dondorp AM, Fanello CI, Hendriksen IC, Gomes E, Seni A, Chhaganlal KD, et al. Artesunate versus quinine in the treatment of severe falciparum malaria in African children (AQUAMAT): an open-label, randomised trial. The Lancet. 2010;376(9753):1647-1657.

[16] Boeuf PS, Loizon S, Awandare GA, Tetteh JK, Addae MM, Adjei GO, et al. Insights into deregulated TNF and IL-10 production in malaria: implications for understanding severe malarial anaemia. Malaria journal. 2012;11(1):1-9.

[17] Taylor T, Olola C, Valim C, Agbenyega T, Kremsner P, Krishna S, et al. Standardized data collection for multi-center clinical studies of severe malaria in African children: establishing the SMAC network. Transactions of the Royal Society of Tropical Medicine and Hygiene. $2006 ; 100(7): 615-622$.

[18] Lell B, Missinou MA, Issifou S, Matsiegui PB, Olola CH, Taylor TE, et al. Assessment of a simplified method for counting leukocytic malaria pigment. The American journal of tropical medicine and hygiene. 2005;73(3):588-592.

[19] Hendriksen IC, Mwanga-Amumpaire J, Von Seidlein L, Mtove G, White LJ, Olaosebikan R, et al. Diagnosing severe falciparum malaria in parasitaemic African children: a prospective evaluation of plasma PfHRP2 measurement. PLoS Medicine. 2012;9(8):e1001297.

[20] Watson JA, Ndila CM, Uyoga S, Macharia A, Nyutu G, Mohammed S, et al. Improving statistical power in severe malaria genetic association studies by augmenting phenotypic precision. eLife. 2021;10:e69698. doi:10.7554/eLife.69698.

[21] Watson JA, Uyoga SA, Wanjiku P, Makale J, Nyutu GM, Mturi N, et al. Improving the diagnosis of severe malaria in African children using platelet counts and plasma PfHRP2 concentrations. medRxiv. 2021;

[22] Taylor TE, Fu WJ, Carr RA, Whitten RO, Mueller JG, Fosiko NG, et al. Differentiating the pathologies of cerebral malaria by postmortem parasite counts. Nature Medicine. 2004;10(2):143-145.

[23] Reyburn H, Mbatia R, Drakeley C, Carneiro I, Mwakasungula E, Mwerinde O, et al. Overdiagnosis of malaria in patients with severe febrile illness in Tanzania: a prospective study. Bmj. 2004;329(7476):1212.

[24] White NJ, Turner GD, Day NP, Dondorp AM. Lethal malaria: Marchiafava and Bignami were right. The Journal of Infectious Diseases. 2013;208(2):192-198. 
[25] Imwong M, Woodrow CJ, Hendriksen IC, Veenemans J, Verhoef H, Faiz MA, et al. Plasma concentration of parasite DNA as a measure of disease severity in falciparum malaria. The Journal of Infectious Diseases. 2015;211(7):1128-1133.

[26] Birbeck GL, Beare N, Lewallen S, Glover SJ, Molyneux ME, Kaplan PW, et al. Identification of malaria retinopathy improves the specificity of the clinical diagnosis of cerebral malaria: findings from a prospective cohort study. The American journal of tropical medicine and hygiene. 2010;82(2):231-234.

[27] Davenport GC, Ouma C, Hittner JB, Were T, Ouma Y, Ong'echa JM, et al. Hematological predictors of increased severe anemia in Kenyan children coinfected with Plasmodium falciparum and HIV-1. American journal of hematology. 2010;85(4):227-233.

[28] Horning MP, Delahunt CB, Bachman CM, Luchavez J, Luna C, Hu L, et al. Performance of a fully-automated system on a WHO malaria microscopy evaluation slide set. Malaria journal. 2021;20(1):1-11.

[29] Amodu O, Adeyemo A, Olumese P, Gbadegesin R. Intraleucocytic malaria pigment and clinical severity of malaria in children. Transactions of the Royal Society of Tropical Medicine and Hygiene. 1998;92(1):54-56.

[30] Wilairatana P, Riganti M, Puchadapirom P, Punpoowong B, Vannaphan S, Udomsangpetch $R$, et al. Prognostic significance of skin and subcutaneous fat sequestration of parasites in severe falciparum malaria. Southeast Asian journal of tropical medicine and public health. 2000;31(2):203-212.

[31] Ochola L, Marsh K, Lowe B, Gal S, Pluschke G, Smith T. Estimation of the sequestered parasite load in severe malaria patients using both host and parasite markers. Parasitology. $2005 ; 131(4): 449-458$.

[32] Mujuzi G, Magambo B, Okech B, Egwang TG. Pigmented monocytes are negative correlates of protection against severe and complicated malaria in Ugandan children. American Journal of Tropical Medicine and Hygiene. 2006;74(5):724-729.

[33] Hänscheid T, Längin M, Lell B, Pötschke M, Oyakhirome S, Kremsner PG, et al. Full blood count and haemozoin-containing leukocytes in children with malaria: diagnostic value and association with disease severity. Malaria Journal. 2008;7(1):1-10.

[34] Fendel R, Brandts C, Rudat A, Kreidenweiss A, Steur C, Appelmann I, et al. Hemolysis is associated with low reticulocyte production index and predicts blood transfusion in severe malarial anemia. PloS one. 2010;5(4):e10038.

[35] Abugri J, Tetteh JKA, Oseni LA, Mensah-Brown HE, Delimini RK, Obuobi DO, et al. Agerelated pattern and monocyte-acquired haemozoin associated production of erythropoietin in children with severe malarial anaemia in Ghana. BMC research notes. 2014;7(1):1-6.

\section{Acknowledgements}

We are very grateful to our many colleagues who conducted the AQ Vietnam, SEAQUAMAT and AQUAMAT trials and to the SMAC network who generously made their anonymised study data openly accessible. This research was funded, in whole or in part, by The Wellcome Trust, Grant 093956/Z/10/C. A CC BY or equivalent licence is applied to author accepted manuscript arising from this submission, in accordance with the grant's open access conditions. NJW is a Principal Research Fellow funded by the Wellcome Trust (093956/Z/10/C). JAW is a Sir Henry Dale Fellow funded by the Wellcome Trust $(223253 / \mathrm{Z} / 21 / \mathrm{Z})$.

\section{Declaration of interests}

The authors have no conflicts of interest. 
SEAQUAMAT

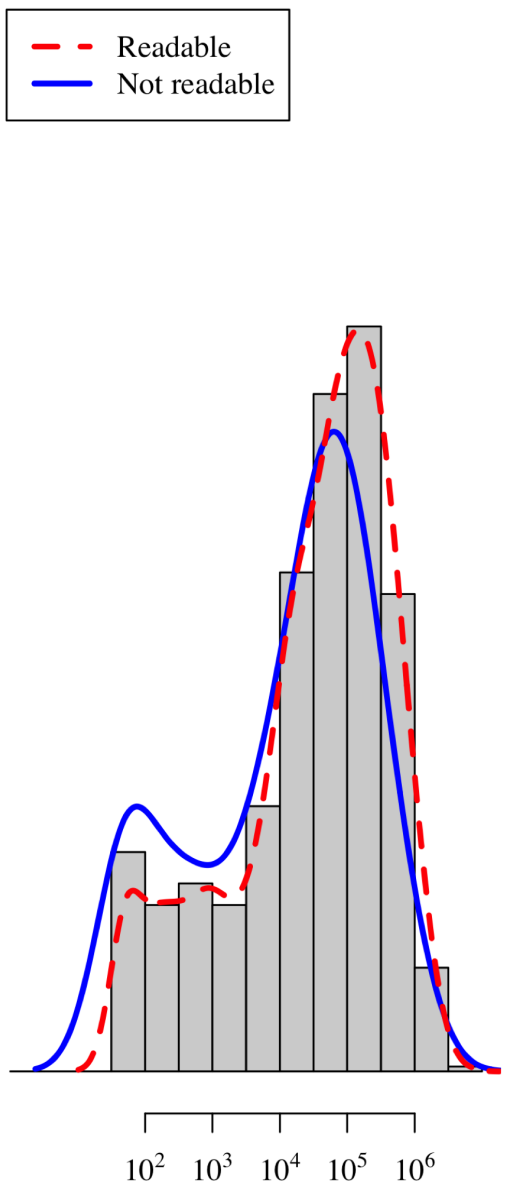

Parasitaemia on admission

\section{AQUAMAT}

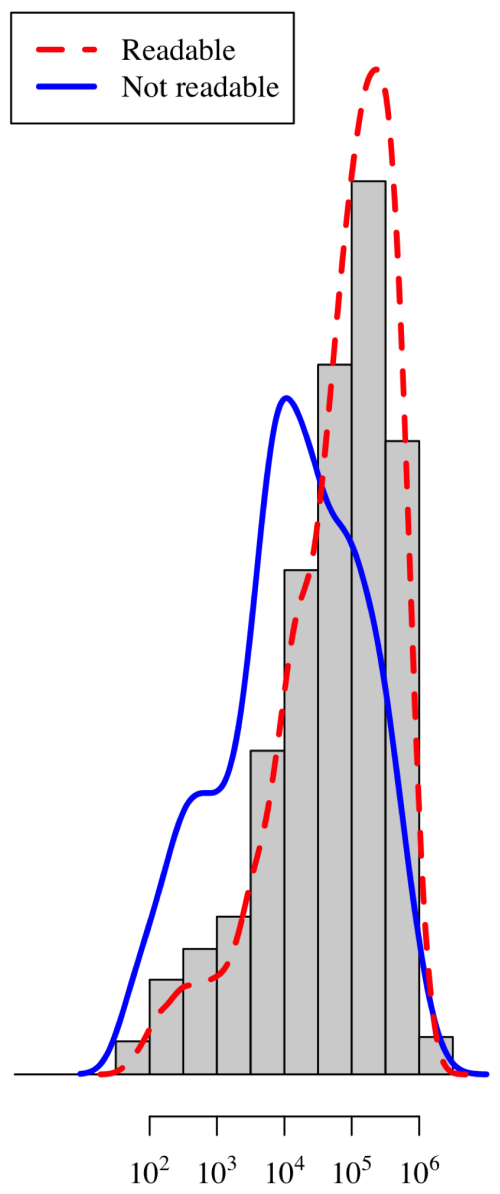

Parasitaemia on admission

Figure S1: Relationship between parasitaemia and data availability on pigment containing PMNs and PMMs in the SEAQUAMAT and AQUAMAT randomised trials.

\section{S1 Systematic review}

From the systematic review we identified 12 studies (including the published results from the AQ Vietnam study) [9, 29, 30, 31, 32, 33, 34, 16, 35, 8].

The majority of these studies had very small sample sizes relative to the AQUAMAT and SEAQUAMAT trials (the median sample size was 46 for the number of severe malaria patients; some studies included uncomplicated malaria). We decided to only attempt to contact study authors to obtain individual patient data for studies with at least 100 patients with severe malaria. The data from Boeuf et al [16] could not be obtained as the principal investigator who had access to the data was deceased. The list of all studies can be found in a supplementary file. 
medRxiv preprint doi: https://doi.org/10.1101/2021.11.30.21267052; this version posted December 7, 2021. The copyright holder for this preprint (which was not certified by peer review) is the author/funder, who has granted medRxiv a license to display the preprint in perpetuity.

It is made available under a CC-BY 4.0 International license.

A: pigment containing PMNs

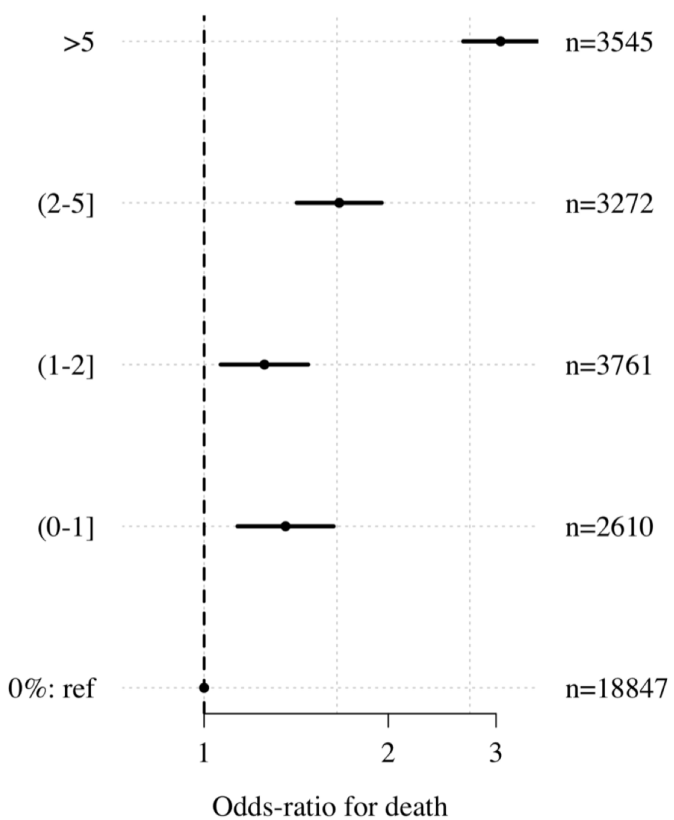

B: pigment containing PMMs

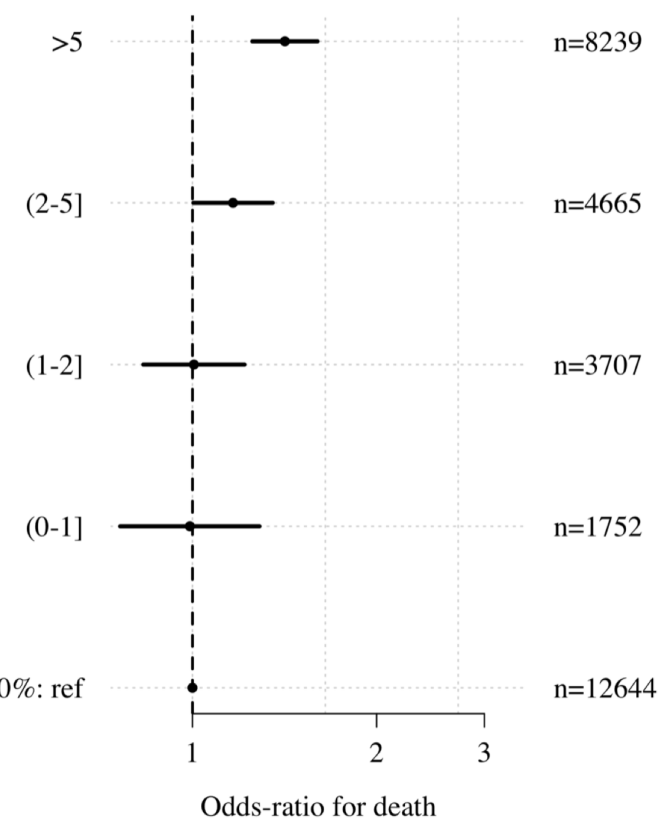

Figure S2: Meta-analysis of the prognostic value of pigment containing PMNs and PMMs stratified into five levels with no pigment as the reference level. Substantial increases in mortality are seen for $>5 \%$ pigment containing PMNs. Point estimates and uncertainty intervals were calculated using a logistic regression model with nested random effects for site, country and study ( $g l m e r$ in $\mathrm{R})$. 
medRxiv preprint doi: https://doi.org/10.1101/2021.11.30.21267052; this version posted December 7, 2021. The copyright holder for this preprint (which was not certified by peer review) is the author/funder, who has granted medRxiv a license to display the preprint in perpetuity.

It is made available under a CC-BY 4.0 International license.

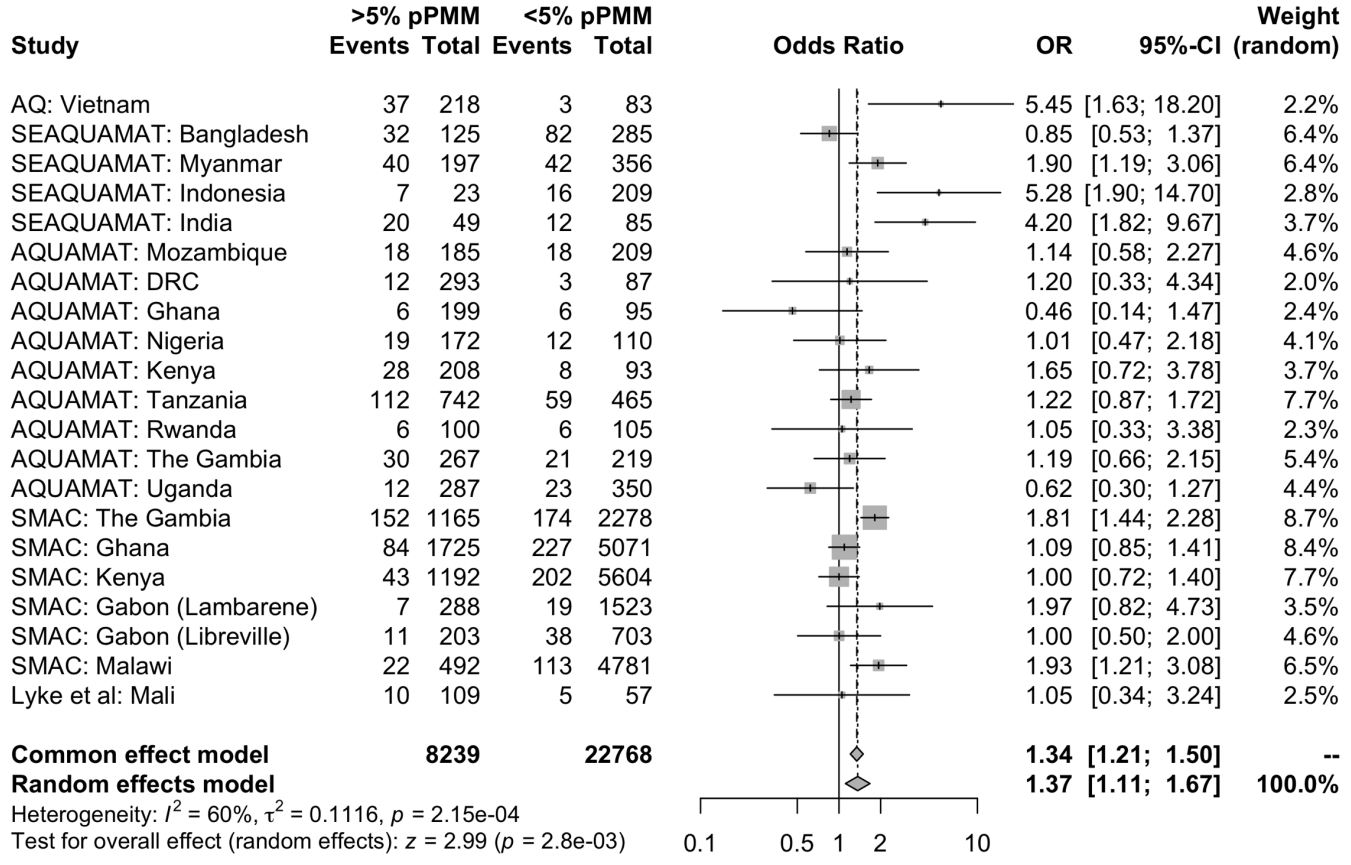

Figure S3: Meta-analysis of the prognostic value for mortality of $>5 \%$ versus $\leq 5 \%$ pigment containing PMMs in 31,007 patients clinically diagnosed with severe falciparum malaria. We show the individual estimates broken down by country of enrolment for each study except for SMAC, Gabon where the distribution of pigment containing PMNs was substantially different between the two sites (Lambaréné and Libreville). 
medRxiv preprint doi: https://doi.org/10.1101/2021.11.30.21267052; this version posted December 7, 2021. The copyright holder for this preprint (which was not certified by peer review) is the author/funder, who has granted medRxiv a license to display the preprint in perpetuity.

It is made available under a CC-BY 4.0 International license .

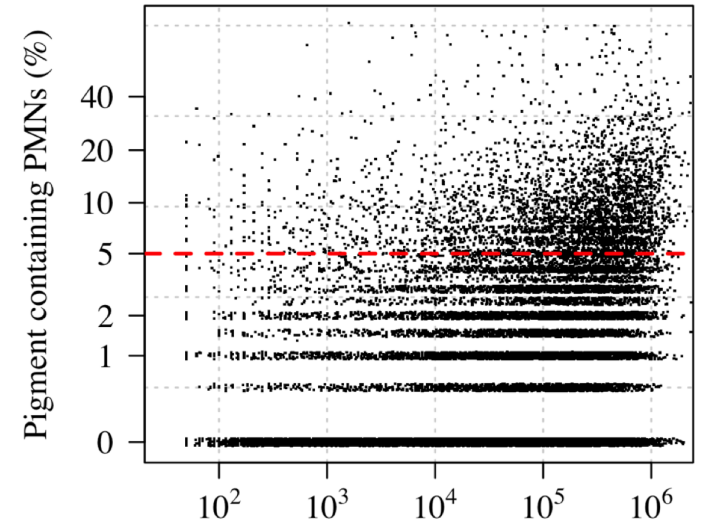

Parasite density (per uL)

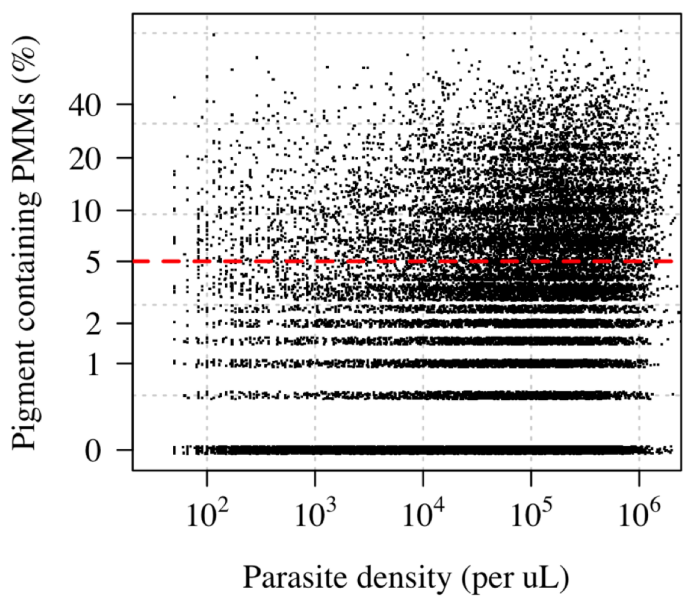

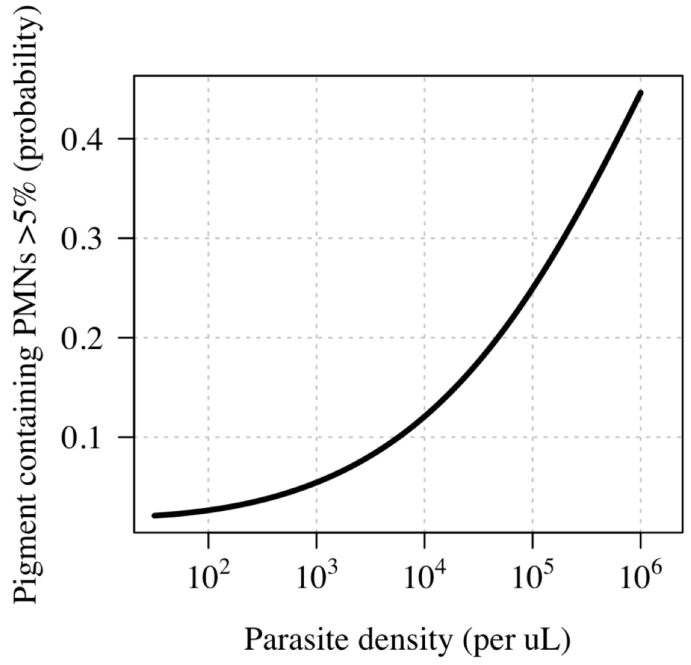

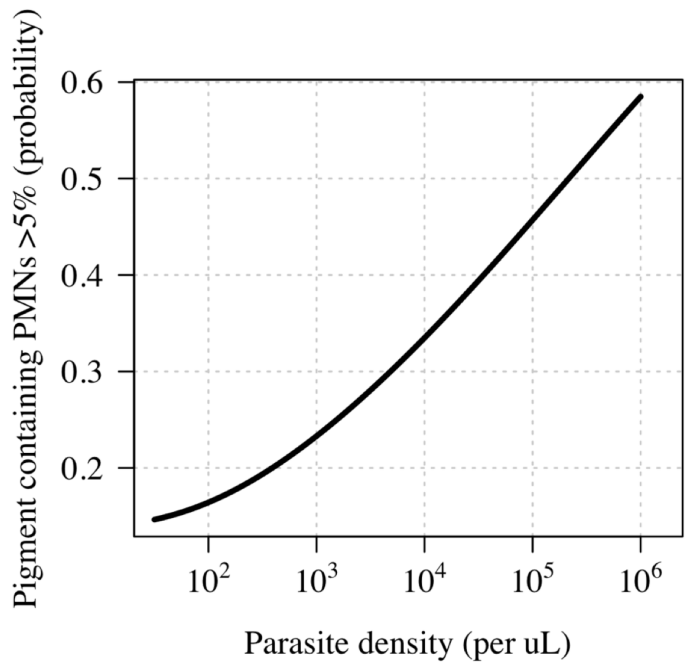

Figure S4: Relationship between the parasite density and the intraleukocytic malaria pigment (top: PMNs, bottom: PMMs). The left panels show scatterplots for the whole pooled data set; the right panels show the probability of having $>5 \%$ pigment containing PMNs or PMMs as a function of the peripheral parasite density (fitted using a logistic regression model with nested random effects for site, country and study). 